\title{
Optimal Multiple Crop Price Hedging: Robust Estimates Under Yield/Basis Risk
}

David R. Fewings, (E-mail: fewings@wwu.edu), Western Washington University Erol A. Peköz, (E-mail: pekoz@ bu.edu), Boston University

\begin{abstract}
This paper examines how commodity futures can optimally be used by farmers to reduce exposure to price risk in the presence of production uncertainty. The multiple-crop hedging problem is modeled under conditions of price risk, production risk, and basis risk. The results are of general significance for producers with concave utility functions of expected wealth. Optimal hedges are obtained that are quantitatively robust for different wealth levels and for variations in utility functions spanning the plausible range from decreasing to increasing relative risk aversion and for relative risk aversion coefficients of any plausible value.

Extensions to the existing literature include a closed form solution that provides robust estimates of optimal hedging strategy for the multiple crop hedging problem under uncertain yields, estimation of the optimal hedge variation as a function of distance from the geographical center of crop production, and optimal hedge estimates for state average crop mixes by state for forty-two states.
\end{abstract}

\section{Introduction}

Casual observation confirms that many entrepreneurs forego market diversification to engage in economic activity that is undertaken with investments that are closely held. In agricultural production, the investment in production assets usually comprises a large fraction of the farmer's wealth. Agency theory provides a strong economic rationale in favor of sole proprietorships or closely held forms of business organization in agriculture, in addition to the important social and cultural reasons. The significant benefits that may be realized from diversification in financial markets are often foregone by farmers in favor of the substantial benefits of sole proprietorships or closely held investments in farm assets. The extent to which uninsured risk is increased due to this trade-off depends upon the availability of insurance options, and the use of other alternatives that are available for effective risk management.

This paper studies the extent to which producers of agricultural field crops should use forward (futures) contracts to reduce exposure to commodity price risk without relinquishing sole ownership for purposes of diversification. As many farmers know from accumulated experience, an attempt to hedge against price uncertainty for crops in production may actually increase exposure to risk because of production uncertainty, and it has the potential for financial disaster in a widespread crop failure. Nevertheless, much of the normative literature to date, the marketing programs of organized futures exchanges, the media at large, and even farm extension programs have for over half a century recommended fully hedging crops in production. Widespread crop failures in major production areas, whether due to adverse weather or infestations, may result in high spot prices due to supply shortages. A farmer with little or no price hedge and a reduced crop is often helped considerably by the higher margins available due to overall supply reductions, especially if the individual is located in close proximity to the major producing region. However, if the farmer is extensively price hedged the losses on forward contracts may more than offset the benefit of higher spot margins. This constitutes a grave risk and may explain the frequently observed reluctance of farmers in general to hedge expected crops that are still in production and subject to yield uncertainty.

The efficacy of the forward market as a means of reducing producer risk through price hedging strategy therefore depends on the interaction between an individual farmer's crop yields and commodity prices. If a farm is located in the main producing region, yields and spot prices will be negatively correlated due to commonly 
experienced production conditions that cause positive correlation between a farmer's crop and total production combined with the normal effects of total supply on prices. This significantly increases the potential hazard of taking a short-hedge position and centrally located farmers should adopt smaller short-hedges than producers in more remote locations. Farmers who are located close to central production regions and who also have relatively greater exposure to production uncertainty, such as those in the northern plains where relatively small variations in rainfall have major effects on yields, should adopt even smaller short hedge positions.

\section{Literature Review}

The problem of hedging agricultural crops in production is analogous to the issue in financial economics concerned with the non-marketable human capital problem first addressed by Mayers (1972). Indeed, the methodology introduced by Mayers to find an optimal solution to that question is extended here to a multivariate analysis of the multiple crop hedging problem. Previous papers dealing specifically with the optimal hedging issue in agricultural production are by McKinnon (1967), Rolfo (1980), Anderson and Danthine (1980), Fewings and Losq (1980), Losq (1982), Lapan, Moschini and Hanson (1991), Sakong, Hayes, and Hallam (1993), Lapan and Moschini (1994), Lence, Sakong and Hayes (1994), Lence and Hayes (1995), Arshanapalli and Gupta (1996), Blank, Carter and McDonald (1997), and Collins (1997).

\section{Producer Hedging under Price and Production Risk}

Assume that the agricultural producer has made a production decision and, having planted her crops, seeks to maximize expected utility of wealth by choosing an appropriate hedge position for each crop for the duration of the production period. Assume also that the producer unwinds the futures positions with offsetting transactions when the harvested crops are delivered for cash. The farmer is thus exposed to the difference between cash and futures prices, known as the basis, at the time of sale. Moreover, harvesting and delivering each crop incurs a marginal cost, leaving an increment to wealth determined by the product of the resulting contribution margins with the yield and acreage devoted to each crop.. Having thus outlined the problem, the farmer should take optimal hedge positions to achieve maximum expected utility of wealth at the time of harvest. The closed form solution is found by finding the first order conditions, subject to the wealth constraint, using Mayers (1972) methodology to achieve tractablility and a closed form solution. It has three terms. The first is the expected yield of the crop concerned, weighted by the proportion of production acreage in that crop. The second determines the optimal adjustment in the short hedge due to the sum of the weighted own and cross-price elasticities of the producer's crop yields, each weighted by the product of the acreage weight, the contribution margin fraction, the expected yield and the expected price per bushel relative to the expected price of the crop concerned. The third component is the covariance of the sum of the first two values (without the expectation operator on the price of the crop concerned) and the product of the farmer's level of absolute risk aversion with a measure of net price and basis volatility.

The result is the estimating equation for the optimal hedge in each crop. A dataset is required to capture the yield and price interaction experiences of history while abstracting from the effects of historical inflation and trends in the data due technological change. The individual components required for each crop include the crop yield per acre, the own and cross elasticities of crop yields with respect to prices of each crop in production, the expected price of each commodity, the unexpected departure of prices from expected values each period, and the extent to which futures unexpectedly differ from spot prices when unwinding of the hedge takes place at harvest time. The second derivative of the utility function with respect to wealth is also present, requiring an assumption concerning the form of the utility function. The calculation of optimal hedges examines utility functions that feature constant, decreasing, and increasing relative risk aversion over the range of plausible coefficients of relative risk aversion.

\section{Empirical Study}

Data were gathered for the period 1973 to 2000 for three major U.S. field crops: corn for grain, soybeans and wheat. These were selected for their economic importance and also because their futures contracts mature in the same months (March, June, September and December). The crop data obtained from the USDA are time series estimates aggregated at the state level for acreages, yields, and production. The Futures Industry Institute provided mid March and mid September values for futures contracts maturing in September as well as USDA estimates of spot prices for the same dates. 


\section{A. Normalization of Spot and Futures Prices}

Spot and futures prices for the three crops were adjusted using the GDP deflator to obtain constant dollar values. September spot prices conditional on March futures were obtained using OLS and scaled to March 2000 values to obtain the series of annual crop price data with stationary distributions. Augmented Dickey-Fuller (ADF) tests for co-integration of September spot and March futures prices easily reject the null hypothesis of unit roots in the residuals, based on McKinnon's (1991) critical value simulation response surfaces. ${ }^{1}$ These results support the co-integration hypothesis that allows regression using integrated series to retain information in the data that is crucial for estimating long run relationships such as price elasticity of yields, a major concern in the study ${ }^{2}$. September futures conditional on March futures were also obtained using OLS and scaled to March 2000 futures values. These data were then used in conjunction with the stationary September spot price series to calculate the September futures basis data for each crop, conditional on March futures.

\section{B. Normalization of Yields}

Historical yield data for the three crops were normalized to abstract from the trends induced by technological changes that have improved agricultural productivity and to eliminate the autocorrelation that is present due to long run weather cycles, variations in soil conditions, water table changes, parasite and disease cycles, and other possible causes of long run yield fluctuations that are thus predictable at shorter intervals. Examination of the autocorrelations for the normalized series for each state's yield data indicated that seven first-difference lag terms are required to achieve white noise in the residuals ${ }^{3}$. As expected, augmented Dicker- Fuller texts on the residuals easily reject the hypothesis of unit roots, validating the normalizing procedure for each crop in each state. The data were normalized on March 2000 levels in order to represent yield data that incorporate technological changes and other trends achieved to date. Stationary crop yield series were thus obtained for each of forty-two crop producing states ${ }^{4}$ for corn, soybeans and wheat crops that were produced continually during 1973-2000. These yield series with stationary distributions are suitable for use in conjunction with the corresponding normalized series of spot and futures prices to estimate optimal crop hedging positions.

\section{Farm Location and Price Hedging}

The intuition described in the introductory section indicates that the efficacy of price hedging is affected adversely by proximity to the center of production. As discussed, this is due to the correlation between unexpected crop production outcomes and spot prices and because correlations are expected to be more negative for production outcomes in the center of the major producing regions that experience common factors such as weather conditions and crop infestations. To explore this intuition, it was necessary to find the geographic center of production of the field crops concerned. The latitude and longitude coordinates at the center of each state were estimated and used to find the location that minimizes the production-weighted distance from each state. The center is about 68 miles south-east of Des Moines, Iowa at latitude $41^{\circ} 19^{\prime}$ and longitude $92^{\circ} 31^{\prime}$.

The correlation coefficients between prices and the state value-weighted production per acre were calculated for each crop in each state. For corn, a regression of correlation versus distance has a very negative intercept (0.57) at mile zero and a steep slope of 0.67 per thousand miles from the center. The intercept has a standard error of only 0.08 and the standard error of the slope is 0.11 . The associated t-values are significant at 6.84 and 6.32, respectively. Similar results were obtained for soybeans and wheat, with the relationship between correlation and distance similarly strong for soybeans and somewhat weaker for wheat. The later is produced over a much broader geographic area.

\section{E. Estimating the Optimal Hedge}

This section employs the historical data described previously to proxy for the joint distribution of the prices and yields of crops of the average farmer in each state. However, it should be emphasized that the estimation procedure can be used equally well for the circumstances of any individual farmer choosing to depart from the state average crop mix. It should also be noted that the same approach is available for any crop with traded futures and a suitable price and yield history from which to obtain the necessary estimates. 
The utility function selected for use in calculating the third component of the optimal short hedge positions was the negative exponential. This function is especially convenient because of its flexibility. A simple change of parameters alters it from a utility function with decreasing relative risk aversion through constant to increasing relative risk aversion. The relative risk aversion coefficient may be changed from a value approaching risk neutrality to very high aversion. For the case of constant relative risk aversion the function simplifies to the more familiar exponential form and as the relative risk aversion coefficient approaches zero the utility function becomes logarithmic.

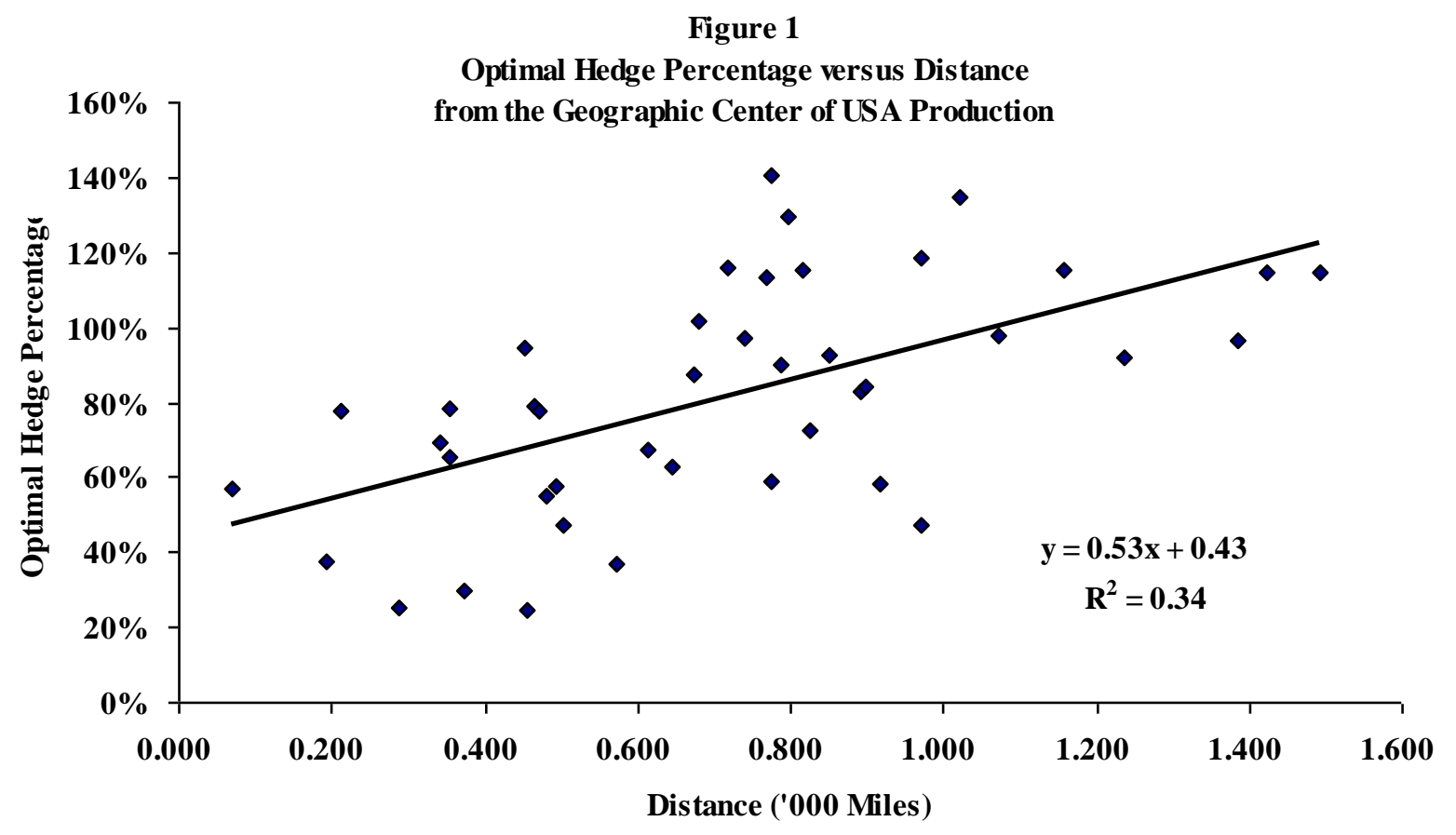

The optimal hedge values were calculated for each state in the study and for each crop that was produced in every year during 1973-2000. To illustrate, in Iowa, the expected corn crop per harvested acre of corn, soybeans and wheat (CSW) is eighty (80.21) bushels. In the absence of production uncertainty, the optimal hedge would be about eighty bushels of corn per acre of CSW. However, given the production uncertainty in Iowa and the own price elasticity of production, the optimal short corn hedge is reduced by seventeen (16.97) bushels. Moreover, this is further reduced by eight (7.80) bushels due to the cross elasticity of soybean production with respect to the price of corn. There is a zero (0.00) adjustment to the hedge for the cross elasticity between wheat production in Iowa and the price of corn. The proportion of acreage devoted to wheat in Iowa is tiny $(0.3 \%)$ and the cross elasticity between Iowa wheat production and the price of corn is also close to zero (-0.03). The optimal short hedge for corn that is independent of the producer utility function is 55.46 bushels. When various utility function parameters are considered, the effects are similar. The negative exponential function reduces the optimal hedge by about two bushels, independent of the relative risk aversion coefficient over a range of 0.5 to 4.5 . The value for the optimal corn hedge for the average Iowa farmer is about 53 bushels ( 52.79 to 53.42 , small differences due to variation in the relative risk aversion coefficients). The optimal corn hedge is $66 \%$ of the expected corn crop. Taking account of soybeans and wheat production, the expected CSW crop value in Iowa is $\$ 264$ per acre and the optimal combined short hedge is in the range of $\$ 149$ to $\$ 152$.. That is $57 \% \pm 1 \%$ of the expected total harvest value, depending on the utility function and degree of risk aversion assumed.

\section{F. Production Location and Optimal Hedge Values}


From examination of the analytical results and the calculations of optimal hedges, it is clear that the expected crop value and the own and cross price elasticities of production play a major role in determining the optimal hedge. As discussed in the introduction, the elasticities are strongest and the optimal short hedge positions are proportionally smaller for farms that are near the geographic center of crop production. Figure 1 is a chart showing the optimal short hedge as a percentage of the expected crop in each state plotted against the distance from the geographic center. The relationship is significant and rather striking. On average, the percentage optimal short hedge increases by 53\% for each thousand miles from Des Moines. The OLS fitted trend line indicates that the optimal short hedge at Des Moines is only $43 \%$ of the expected harvest, on average.

Figure 7

Optimal Combined Corn, Soybean and Wheat Short Hedge for the Average Crop Mix in Each State as a Percentage of the Expected Crop Value

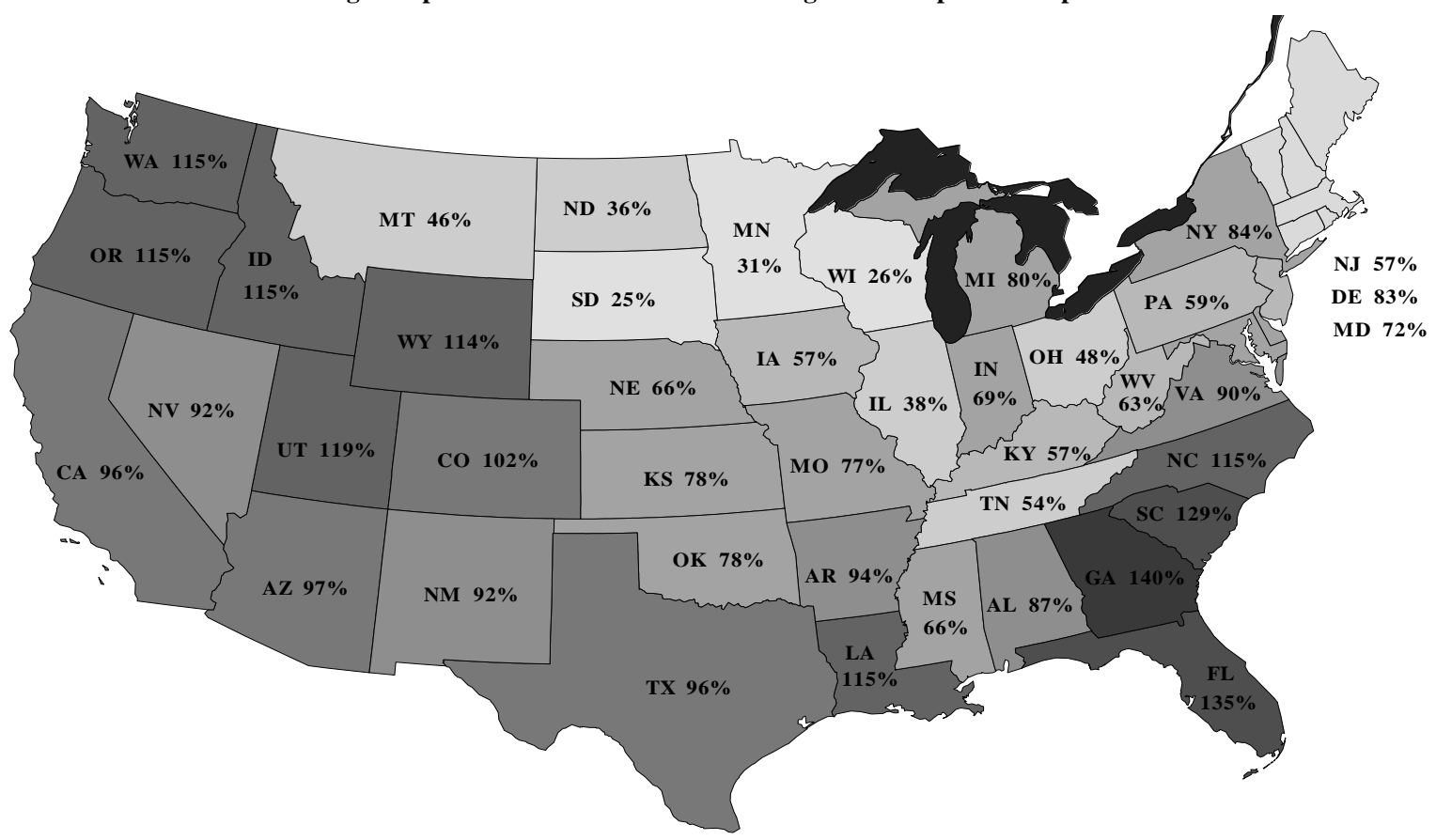

The combined optimal percentage short hedge for each state is presented on the map in Figure 7. The visual results are again striking. The optimal hedge percentages are much smaller in the geographic center of production. Short hedge ratios are highest in the mountain and basin states in the West and in the Southeast areas of the country, areas that are distant from major production areas.

\section{Conclusion}

This paper successfully determines how commodity futures should be used by farmers to manage price risk for crops in production where the yield is still uncertain and basis risk is the norm. The results are of general significance for producers with concave utility functions of expected wealth. The optimal hedges obtained are quantitatively robust for different wealth levels and for variations in utility functions spanning the plausible range from decreasing to increasing relative risk aversion and for relative risk aversion coefficients of any plausible value. The greatest variation in hedge optima are due to regional differences. Broad weather systems and major infestations that affect the crops over an area of several states can have good or bad effects for major production regions. Consequently, price elasticity of yields are more negative for producers in the major production region and optimal price hedges are reduced there accordingly.

\section{References}

1. Anderson and Danthine (1980). Hedging and Joint Production: Theory and Illustrations. Journal of Finance, 35 pp. 487-498. 
2. Arshanapalli and Gupta (1996). Optimal Hedging under Output Price Uncertainty. European Journal of Operations Research, 95: pp. 522-536.

3. Collins (1997). Toward a Positive Economic Theory of Hedging. American Journal of Agricultural Economics, 79: pp. 488-499.

4. Fewings and Losq (1980). Hedging by Primary Producers Faced with Price and Yield Uncertainty. Unpublished manuscript, McGill University.

5. Lapan and Moschini (1994). Futures Hedging under Price, Basis, and Production Risk. American Journal of Agricultural Economics, 76: pages 465-477.

6. Lapan, Moschini, and Hanson (1991). Production, Hedging, and Speculative Decisions with Options and Futures Markets. American Journal of Agricultural Economics, Feb., pp. 67-74.

7. Lence and Hayes (1995). Optimal Hedging under Forward-Looking Behavior. The Economic Record, volume 71, No. 215, pp. 329-342.

8. Lence, Sakong, and Hayes (1994). Multi-. Production with Forward and Options Markets. American Journal of Agricultural Economics, 76: pp. 286-295.

9. Losq, E. (1982). Hedging with Price and Output Uncertainty. Economics Letters, 10: pp. 65-70.

10. Markowitz , H.(1959). Portfolio Selection: Efficient Diversification of Investment. New York: Wiley, 1959.

11. Mayers, D. (1972). Nonmarketable Assets and Capital Market Equilibrium under Uncertainty, in Jensen (editor). Studies in the Theory of Capital Markets. New York: Praeger.

12. McKinnon (1967). Futures Markets, Buffer Stocks, and Income Stability for Primary Producers, Journal of Political Economy, 75: pp. 844-861.

13. Pindyck, Robert S. and Daniel L. Rubinfeld, Econometric Models and Economic Forecasts, $4^{\text {th }}$ ed., IrwinMcGraw Hill, Boston: 1998.

14. Rolfo (1980). Optimal Hedging under Price and Quantity Uncertainty: the Case of the Cocoa Producer. Journal of Political Economy, volume 88, No. 1, pp. 101-116.

15. Sakong, Hayes, Hallam (1993). Hedging Production Risk with Options. American Journal of Agricultural Economics, 75: pp. 408-415.

\footnotetext{
${ }^{1}$ Regressions were also run that included both the March six-month T-bill rate and futures. These also supported the hypothesis of cointegration, however the T-bill rate entered the regressions with insignificant coefficients.

${ }^{2}$ Co-integrating regressions were calculated that included six-month March T-Bill rates. Although the interest rates had coefficients of the correct sign, they did not enter the regressions with significant values or explanatory power.

${ }^{3}$ The long cycle variations in weather and soil conditions due to phenomena such as El Nino support the need for long lags to remove autocorrelation from residual error terms. In order to maintain comparability between states, the same seven-year lag structure was employed for all crops and all states in the study. In cases where a shorter lag would be adequate, the use of extra lags causes no significant adverse effects. Insufficient use of the lag structure, however, would invalidate tests for unit roots.

${ }^{4}$ Alaska, Connecticut, Hawaii, Maine, Massachusetts, New Hampshire, Rhode Island, and Vermont were excluded due to lack of sustained production of at least one crop in the study for the period 1973-2000.
} 